\title{
O pensamento sistêmico no processo de design de livros digitais: a proposta "Framebook"
}

\section{The systemic thinking in the digital book design process: the "Framebook" proposal}

\author{
Maurício Elias Dick, Universidade Federal de Santa Catarina \\ mauricioedick@gmail.com \\ Berenice Santos Gonçalves, Universidade Federal de Santa Catarina \\ berenice@cce.ufsc.br
}

\section{Resumo}

A consolidação do livro digital depende da percepção de um sistema definido por modos de operação, disseminação e consumo quase totalmente integrados digitalmente, transformando o meio editorial de maneira radical. Diante disso, é preciso repensar o processo de design do livro digital sob uma nova perspectiva para que se obtenha uma visão clara das especificidades destes artefatos e da complexidade do cenário editorial. Nessa direção, esta pesquisa teve como objetivo propor um framework para o processo de design do livro digital, a partir de uma perspectiva sistêmica. Para tal, realizou-se uma revisão de literatura, seguida de entrevistas com profissionais que atuam no segmento de livros digitais. Os resultados desses procedimentos deram origem a um conjunto de premissas que alicerçaram a construção da primeira versão do framework, posteriormente refinado em um grupo focal com designers. Sua versão final é composta por 13 fatores inter-relacionados, organizados em três grupos: primários (Conteúdo, Tecnologia e Leitor), secundários (Autor, Outros Agentes, Editor, Gestão do Negócio e Distribuidor) e terciários (Livro Impresso, Direitos Digitais, Livros Digitais Similares e Players Tecnológicos).

Palavras-chave: Livro Digital, Processo de Design, Pensamento Sistêmico, Framework

\begin{abstract}
The consolidation of the digital book depends on the perception of a system defined by modes of operation, dissemination and consumption that are almost entirely digitally integrated, transforming the editorial environment radically. Given this, it is necessary to rethink the digital book design process under a new perspective in order to obtain a clear vision of the specificities of these artifacts and the complexity of the editorial scenario. In this direction, this research aimed to propose a framework for the digital book design process, from a systemic perspective. For this, a literature review was carried out, followed by interviews with professionals working in the digital books segment. The results of these procedures gave rise to a set of premises that underpinned the construction of the first version of the framework, later refined in a focus group with designers. Its final version is composed by 13 interrelated factors, organized in three groups: primary (Content, Technology and Reader), secondary (Author, Other Agents, Publisher, Business Management and Distributor) and tertiary (Printed Book, Digital Rights, Similar Digital Books and Technological Players).
\end{abstract}

Keywords: Digital Book, Design Process, Systemic Thinking, Framework 


\section{Introdução}

Os livros digitais ultrapassaram sua fase inicial de consolidação. Na atualidade, estes artefatos são disseminados por meio de plataformas comuns a outras mídias digitais, coexistem em múltiplos formatos e são comercializados em uma variedade de formas. O conjunto tecnológico, os players ${ }^{1}$ envolvidos, os processos de criação e os modelos de negócio e distribuição foram alterados e o resultado é um sistema definido por modos de operação, disseminação e consumo quase totalmente integrados digitalmente, transformando o meio editorial de maneira radical (WISCHENBART, 2018).

De acordo com Polo Pujadas (2016), as mudanças tecnológicas têm introduzido novas dinâmicas para o meio editorial. Para a autora (POLO PUJADAS, 2016), o setor está se conscientizando cada vez mais das transformações que implicam o avanço das novas tecnologias e dos meios digitais. Este cenário leva a repensar a própria natureza e o conceito de livro, o qual emerge no ambiente digital como um bem informacional em rede, onde as capacidades interativas e a ligação ao sistema externo são sua essência (MENDONÇA, 2015). Nesse contexto, o livro digital se torna um sistema aberto, versátil e em contínua evolução (CORDÓN-GARCÍA et al., 2013).

Assim, importantes mudanças afetam os agentes da cadeia editorial como um todo considerando autor, editor, distribuidor, biblioteca e leitor - e alteram os processos de concepção, produção e distribuição, como também a finalidade e a cultura associada ao livro (CORDÓNGARCÍA, 2016; CARDOSO, 2015). Enquanto os papéis dos agentes tradicionais sofreram novas significações, relações existentes entre elos da cadeia editorial foram desfeitas e outras novas foram construídas (PWC, 2010). A possibilidade de separação entre suporte tecnológico e conteúdo (DUBINI, 2013) permitiu novos modos de disponibilizar o livro no contexto digital, com a multiplicação das formas de distribuição, oferta e acesso, enquanto os players tecnológicos (tais como Google, Amazon, Facebook, Apple) passaram a fazer parte da cadeia editorial e provocaram um efeito de desintermediação (ARÉVALO; CORDÓN-GARCÍA; DÍAZ, 2014). Por sua vez, todo este contexto de mudança alterou em parte a função do editor e transformou também o papel do leitor, tornando-o mais ativo no processo de autoria, por exemplo.

Para Procópio (2013), vive-se um momento de transição de paradigma no setor de edição, caracterizado por um novo modo de escrever, publicar, circular e ler livros, e, como aponta Mendonça (2015), as alterações que incidem sobre o contexto editorial fazem com que esse meio se configure mais como um sistema, uma rede. Tendo em vista as dinâmicas e complexidades atuais, é preciso repensar como essas conjunturas de mudança para os livros digitais são percebidas (WISCHENBART, 2018) e a forma de tratar o problema editorial deve ser diferente (SILVA; BORGES, 2016).

Tal como em outras situações, o produto não é um elemento isolado, mas integra uma realidade imbricada e mutante (MORAES, 2010) em que as partes atualizam entre si dependência e independência simultaneamente. Diante desse cenário, no contexto de design, é fundamental perceber o mundo de modo mais alargado para compreender a dinâmica que gira em torno do

\footnotetext{
${ }^{1}$ No contexto desta pesquisa, compreende-se o termo "players" como participantes, agentes no mercado.
} 
artefato em desenvolvimento (MORAES, 2010). É preciso mudar a visão de objetos para relações, considerando as partes, mas também o todo, adotando um pensamento sistêmico (CAPRA; LUISI, 2014).

Sob diferentes denominações, tais como "pensamento sistêmico", "visão sistêmica" e "abordagem sistêmica", este modus operandi se ocupa do contexto e das relações em um sistema, considerando os elementos e o todo (BISTAGNINO, 2009). O pensamento sistêmico se baseia em ideias sistêmicas como a primazia dos relacionamentos, da circularidade, da rede e dos processos (ANDRADE, 2014), envolvendo um pensamento que ocorre mediante relações, padrões e contextos (CAPRA; LUISI, 2014). Tratado como uma mudança de ponto de vista, o modo de pensar sistêmico se aplica a diversas disciplinas como forma de abordagem dos problemas complexos do século XXI (CAPRA; LUISI, 2014).

Nessa perspectiva, o pensamento sistêmico contribui para a percepção ampliada dos elementos e das relações que influenciam o processo de design do livro digital, pois esta forma de pensar leva a uma capacidade de perceber, modelar e avaliar as situações de modo expandido (ANDRADE, 2014). De maneira geral, o pensamento sistêmico propõe uma recomposição do todo considerando os relacionamentos entre as partes. Isto permite reconhecer suas redes complexas, além da importância das relações circulares e da relevância da dinâmica e dos processos para compreender os sistemas (ANDRADE, 2014).

Frente ao exposto, é preciso reforçar a atenção ao processo de design do livro digital sob uma perspectiva sistêmica para compreender a dinâmica dos elementos que lhe exercem influência. Isso demanda reorganizar a prática e rever a visão editorial tradicional, uma vez que fica evidente a fragilidade dos procedimentos atuais ao transpô-los para o contexto digital, dadas todas as modificações decorrentes dessa transição em curso. Na atual conjuntura, o processo de design do artefato demanda contemplar um conjunto maior de elementos inter-relacionados em suas decisões projetuais para projetar livros digitais considerando as especificidades destes artefatos e a complexidade vigente do cenário editorial.

Nessa direção, portanto, esta pesquisa teve como objetivo propor um framework ${ }^{2}$ para o processo de design do livro digital, a partir de uma perspectiva sistêmica. Para tal, foram realizadas entrevistas com profissionais que atuam no desenvolvimento de livros digitais, cujos resultados juntamente com os achados da literatura deram origem a um conjunto de premissas que alicerçaram a construção da primeira versão do framework, ajustado e refinado a partir de contribuições de designers no contexto de um grupo focal. Como bases teóricas, utilizou-se o pensamento sistêmico para obter uma visão ampliada das particularidades do livro digital e das mudanças decorrentes no contexto editorial.

\section{Procedimentos metodológicos}

\footnotetext{
${ }^{2}$ Um framework é uma representação visual de um sistema que mostra seus elementos e evidencia suas relações (IDEO, 2015). Logo, é uma abstração que apresenta tanto estrutura (partes) como dinâmica (interrelações) (DICK; GONÇALVES, 2019).
} 
De natureza aplicada, esta pesquisa adotou uma abordagem qualitativa e foi estruturada em cinco principais fases, a saber: revisão de literatura, entrevistas com profissionais, elaboração inicial do framework, verificação de validade do framework e finalização do framework (Figura $1)$.

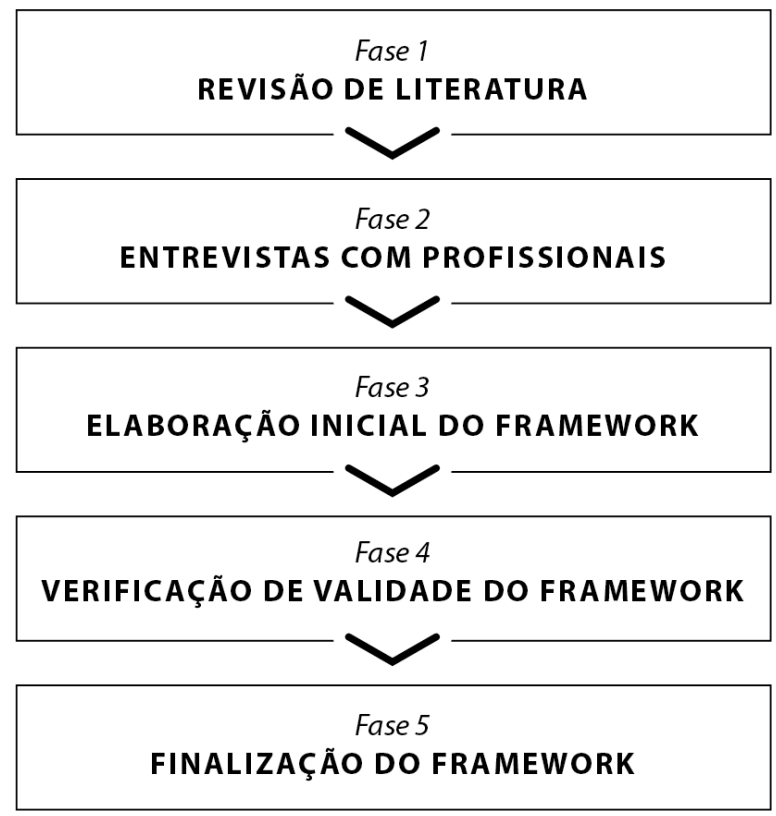

Figura 1: Fases da pesquisa. Fonte: autores.

\section{Fase 1: Revisão de Literatura}

Os principais autores que embasaram a revisão de literatura referente às especificidades do livro digital e às transformações no sistema editorial foram Furtado (2009), Thompson (2005, 2012), Mod (2011, 2012), Procópio (2013), Pinsky (2013) Dubini (2013), Clark e Phillips (2014) - incluindo Phillips (2014) -, Rodrigues (2015), Silva e Borges (2016), Cordón-García (2016) também por meio de Cordón-García et al. (2013) e Arévalo, Cordón-García e Díaz (2014) - e De Voldere et al. (2017). Com base nas fontes levantadas, grande parte à luz da edição de livros, não ficaram totalmente explícitas as implicações dos achados para o processo de design, o que justificou a realização de entrevistas com profissionais.

\section{Fase 2: Entrevistas com Profissionais}

Foram realizadas nove entrevistas semiestruturadas com profissionais atuantes no segmento de livros digitais, que representavam sete empresas brasileiras e duas estadunidenses ${ }^{3}$. $\mathrm{O}$ cerne das entrevistas consistiu em perguntas que permitiam identificar que elementos e relações

\footnotetext{
${ }^{3}$ Três participantes representavam editoras tradicionais e seis, empresas de tecnologia e/ou editoras independentes. Quanto ao tipo de livro digital produzido pelas empresas dos entrevistados, duas produziam livros aplicativos, uma produzia livros baseados em linguagem web e seis desenvolviam livros digitais de layout fluído e/ou fixo, majoritariamente em formato ePUB.
} 
influenciavam o processo de design do livro digital na conjuntura das práticas profissionais dos participantes, buscando igualmente aprofundar o levantamento bibliográfico prévio.

Para o tratamento dos dados qualitativos, fez-se uso do método de análise de conteúdo proposto por Bardin (2016). Para auxiliar nesta etapa, nas entrevistas com profissionais, utilizouse o software para análise de dados qualitativos ATLAS.ti e a técnica específica de análise categorial (BARDIN, 2016). Nessa direção, as falas dos participantes foram codificadas e estes códigos foram relacionados com os temas das perguntas. A partir da proximidade/similaridade entre códigos, foi possível categorizá-los em famílias temáticas (Figura 2).

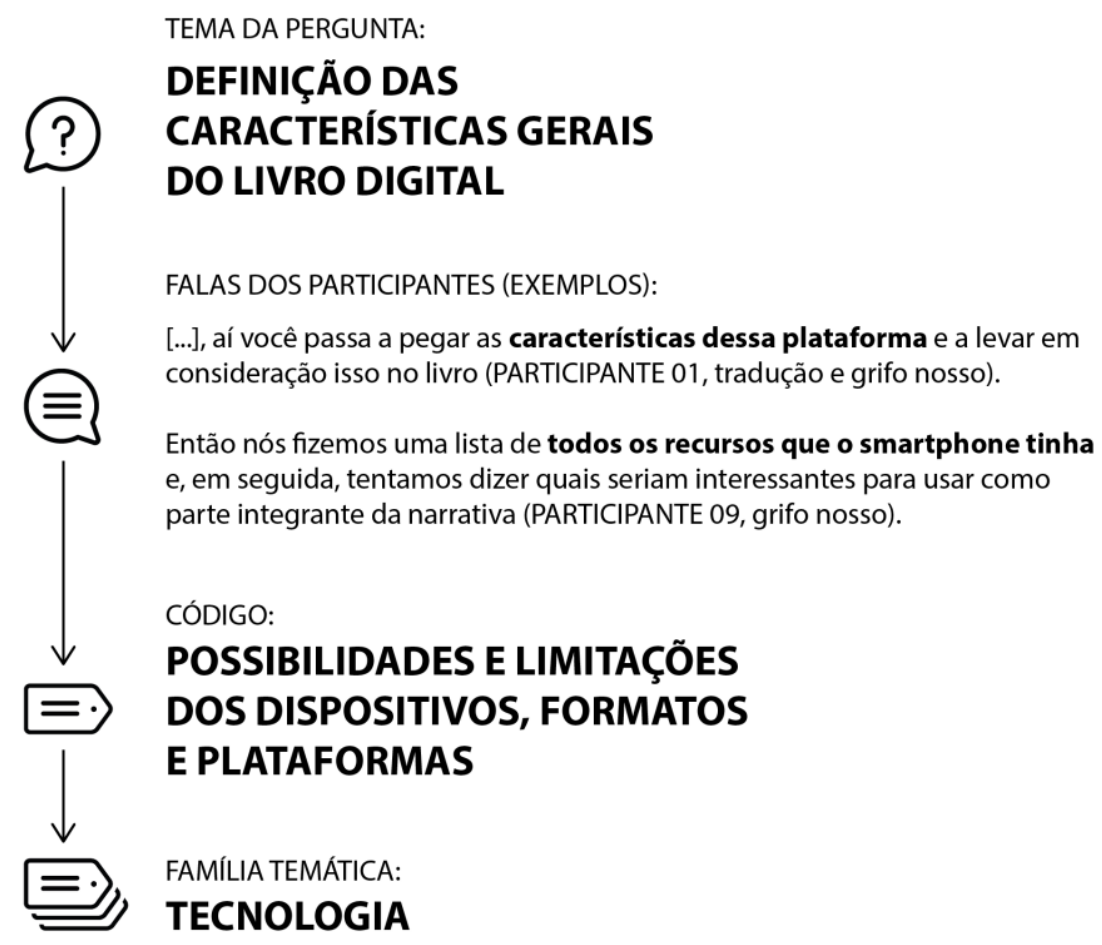

Figura 2: Exemplo do processo de análise categorial. Fonte: autores.

A repetição das famílias temáticas nas falas dos participantes permitiu identificar e sistematizar os principais fatores levados em consideração no processo de design do livro digital. Assim, conforme seu grau de recorrência, estes fatores foram classificados em três diferentes níveis: primários, secundários ou terciários. A título de exemplo, Leitor, Conteúdo e Tecnologia foram as famílias temáticas mais citadas pelos entrevistados, configurando, portanto, o grupo de fatores primários.

\section{Fase 3: Elaboração Inicial do Framework}

A partir dos resultados das fases anteriores, foram formuladas premissas para o framework que orientaram o desenho de sua primeira versão, contemplando uma visão sistêmica dos elementos que influenciam o processo de design do livro digital. No total, foram formuladas onze premissas conceituais e três premissas dirigidas ao processo de design do livro digital (Figura 3). 


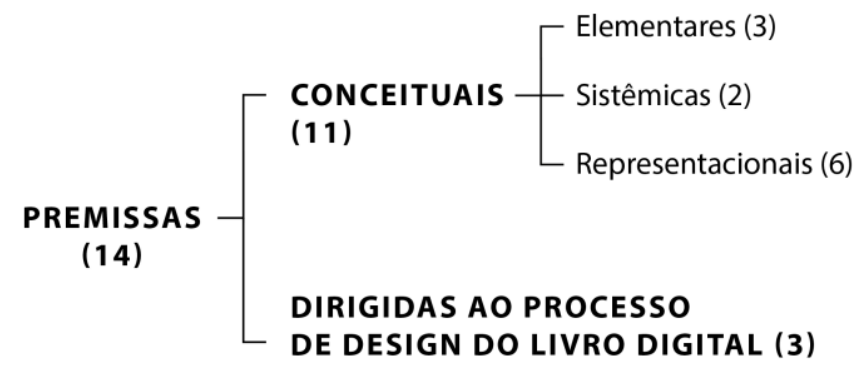

Figura 3: Categorização das premissas do framework. Fonte: autores.

Com base na análise das premissas, definiu-se que as entidades do framework seriam todos os fatores explicitados nas premissas dirigidas ao processo de design do livro digital (identificados na literatura e nas entrevistas com profissionais). Para completar os grafos, estas entidades foram conectadas por linhas que representavam qualitativamente a intensidade das suas relações. Já as regiões foram demarcadas pela relevância dos grafos para o processo de design do livro digital (fatores primários, secundários e terciários). Destaca-se que as relações e as regiões também advieram da inferência dos dados obtidos na literatura e nas entrevistas com profissionais.

\section{Fase 4: Verificação de Validade do Framework}

Para verificar a validade externa $a^{4}$ da primeira versão do framework, foi realizado um grupo focal com a participação de cinco designers brasileiros pesquisadores do livro digital ou experientes na área editorial ou digital do Design. Desse modo, o procedimento foi dividido em três partes: apropriação, discussão e avaliação. Tanto para a discussão quanto para a avaliação, foram elaboradas questões abertas, pois estas permitiriam conhecer de modo mais aprofundado as opiniões dos participantes (DUARTE; BARROS, 2012).

De maneira geral, as contribuições dos designers puderam ser categorizadas em três grupos: quanto à explicitação da utilidade e do propósito do framework, quanto à redução da complexidade da representação visual e quanto a sugestões de conteúdo, especialmente no que se refere à nomenclatura e à relevância de parte dos fatores presentes na primeira proposição. Estas, por sua vez, direcionaram modificações no framework que permitiram chegar em sua versão final na fase posterior da pesquisa.

\section{Fase 5: Finalização do Framework}

Na última fase do estudo, o framework foi ajustado, refinado e nomeado "Framebook", estando detalhado no tópico seguinte. É importante ressaltar que, apesar do processo linear, a formulação da proposição final contou com a confrontação e o inter-relacionamento dos diferentes resultados no decorrer da pesquisa.

\section{Resultados}

\footnotetext{
${ }^{4}$ A validade externa se refere à possibilidade de descrever os resultados, compreendê-los e extrapolá-los para outras situações (OLLAIK; ZILLER, 2012).
} 
Framebook é um framework explicativo, que tem por objetivo auxiliar na percepção da complexidade e no planejamento do processo de design de livros digitais. Para tal, o framework se apresenta como uma representação visual, em forma de diagrama, do sistema dos fatores que influenciam este processo. A proposição é direcionada a designers, tanto no contexto de equipes em empresas de tecnologia e editoras, quanto de atuação individual em um cenário independente. De igual modo, o Framebook é dirigido tanto ao designer que executa quanto àquele que coordena o processo, visto que muitas vezes este profissional é quem organiza e estrutura toda a realização da obra.

Os fatores trazidos no framework estão agrupados em três regiões: primários, secundários e terciários. Os fatores primários correspondem ao Conteúdo, à Tecnologia e ao Leitor. Estes são essenciais a todo o processo de design do livro digital, uma vez que o sistema deste artefato é condicionado pela forma como cada um destes fatores torna possível a relação entre os demais ${ }^{5}$. Nessa lógica, os fatores primários compõem o cerne do framework, onde as decisões de design dizem respeito ao binômio tecnologia/conteúdo (forma/função) e, da relação indissociável com o leitor, surge a concepção conceitual da obra.

Os fatores secundários são aqueles cuja relevância geral é menor que dos fatores primários, mas que exercem influência considerável nas decisões de design relativas à essência do livro digital (conteúdo e tecnologia). São eles: Autor, Outros Agentes (designers, desenvolvedores, revisores, tradutores, etc.), Editor, Gestão do Negócio, Distribuidor e Biblioteca. Já os fatores terciários correspondem ao Livro Impresso, aos Direitos Digitais, aos Livros Digitais Similares e aos Players Tecnológicos (como empresas de tecnologia e fabricantes de dispositivos). Estão à margem do sistema, mas, ainda assim, devem ser considerados no processo de design do livro digital.

No entanto, pensar sistemicamente é pensar de forma contextual, onde as propriedades das partes só podem ser entendidas a partir da organização do todo, em um contexto mais amplo. Assim, não é possível considerar as partes sem considerar o todo, ou seja, a relação entre as partes. Nessa direção, no Framebook, os fatores primários, secundários e terciários estão relacionados entre si (Figura 4).

\footnotetext{
${ }^{5} \mathrm{O}$ livro digital é condicionado pela forma como: (i) o conteúdo possibilita a relação tecnologia/leitor; (ii) a tecnologia possibilita a relação conteúdo/leitor; e (iii) o leitor possibilita a relação conteúdo/tecnologia.
} 


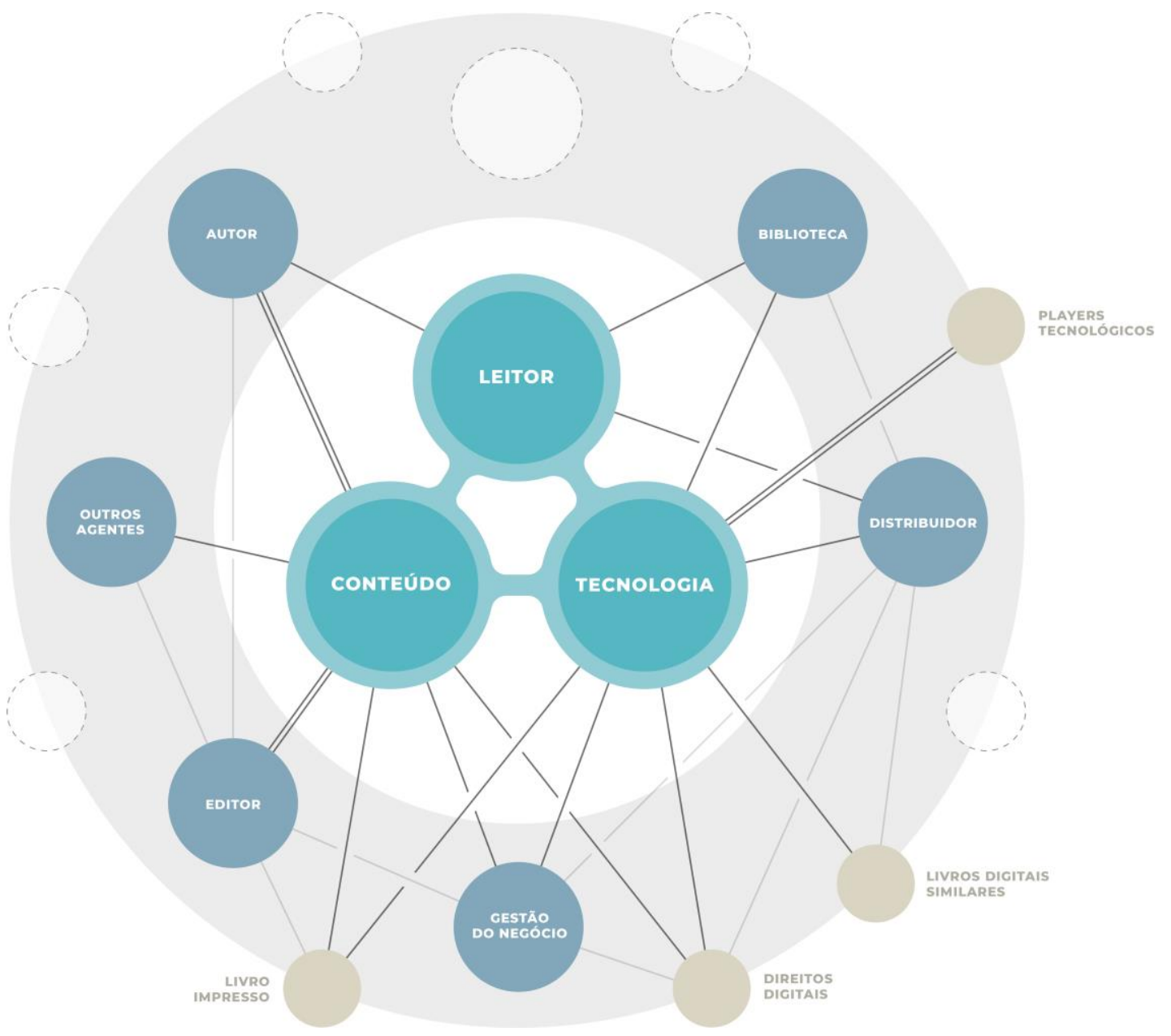

Figura 4: Versão final do Framebook. Fonte: autores.

Como pode ser percebido, essas relações em rede conduzem a um pensamento não-linear e são classificadas em quatro tipos. A relação dos fatores primários entre si é chamada relação indissociável, pois no processo de design do livro digital não é possível considerar um fator primário sem ponderá-lo com os demais ou excluí-lo do processo. Conteúdo, Tecnologia e Leitor são entidades inseparáveis e inter-relacionadas na existência do livro digital. As demais relações presentes no Framebook são a relação intensa, a relação moderada e a relação leve, sendo as relações intensas aquelas de maior força entre os fatores após a relação indissociável.

Em função da hierarquia existente entre os fatores e entre as relações, o Framebook estabelece diferentes prioridades para se ponderá-los. Primeiramente, é necessário considerar os fatores primários e as relações entre eles, em seguida as relações intensas destes com quaisquer fatores. $\mathrm{Na}$ sequência, tem-se as relações moderadas dos fatores primários com os fatores secundários e, posteriormente, as relações moderadas com os fatores terciários. Por último, consideram-se as relações leves entre os fatores secundários e destes com os fatores terciários ${ }^{6}$. A Figura 5 ilustra essa hierarquização.

\footnotetext{
${ }^{6}$ Ressalva-se que o framework não explicita as relações dos fatores terciários entre si, dado o excesso de complexidade que adicionariam à proposição, porém elas podem existir.
} 

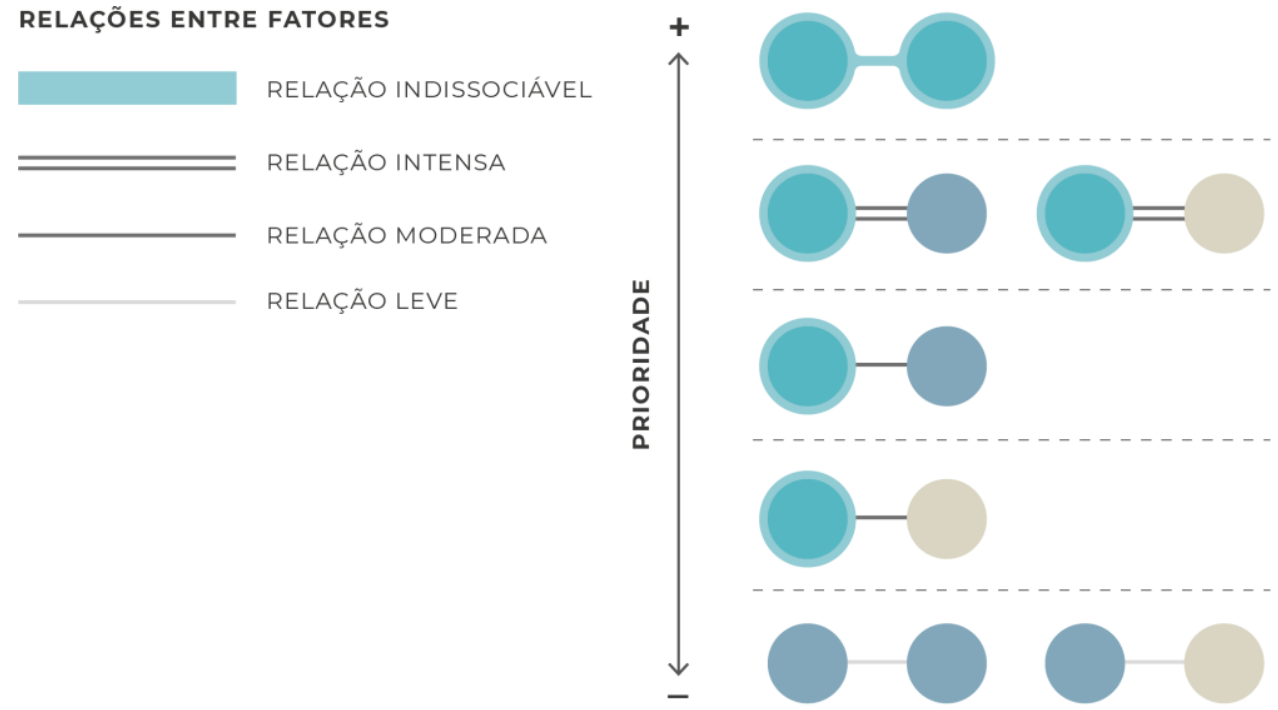

Figura 5: Prioridade das relações entre os fatores. Fonte: autores.

Cabe então detalhar as relações entre os fatores que estão explícitas no Framebook ${ }^{7}$. Ao se considerar as decisões de design relativas ao conteúdo - no que tangem as atividades de preparação e adequação do mesmo, como a definição, organização e estruturação do conteúdo e a definição de mídias e recursos interativos -, é importante ao designer ponderar as próprias especificidades deste fator, junto dos aspectos da tecnologia e do leitor. Em um segundo momento, deve-se apreciar as opiniões e decisões do autor (ou da equipe que produz o conteúdo) e do editor, bem como de outros agentes envolvidos no processo (sua própria opinião, de desenvolvedores, revisores, tradutores, etc.).

A gestão do negócio - estratégias, políticas e limitações que dizem respeito ao negócio e à empresa, fora do escopo de design - também deve ser considerada nas decisões referentes ao conteúdo, dado seu impacto em termos de custo de produção e viabilidade comercial. Igualmente, o nível de correspondência com o livro impresso equivalente, quando este existir, pode ser um fator influente nas definições de conteúdo, assim como determinadas questões relacionadas com os direitos digitais, como a existência de permissões de uso do mesmo.

Considerando-se as decisões de design relativas à tecnologia - que dizem respeito às definições de formato, suporte tecnológico e funcionalidades, alinhadas aos recursos interativos, por exemplo -, é preciso que o designer analise os aspectos deste fator junto às especificidades do conteúdo e do leitor. Em um segundo momento, ele deve ponderar suas decisões em relação à evolução tecnológica e às formas de arquivamento e preservação da obra em desenvolvimento, questões ligadas aos players tecnológicos. Do mesmo modo é preciso ponderar as imposições e limitações das plataformas de distribuição, das bibliotecas (quando for o caso), além de considerar, mais uma vez, a gestão do negócio, dado seu impacto em termos de custo de produção

\footnotetext{
${ }^{7}$ Não se busca aqui explicar todas as possíveis ponderações a serem realizadas entre os fatores relacionados no Framebook. Cabe ao designer ou à equipe de design considerar as inter-relações que forem pertinentes ao seu projeto, bem como criar novas associações a partir das conexões evidenciadas pela proposição.
} 
e viabilidade comercial. O grau de fidelidade com o livro impresso equivalente, caso houver, e as restrições ou definições ligadas aos direitos digitais também podem ser fatores influentes nas decisões quanto à tecnologia. Além disso, as soluções recorrentes em livros digitais similares disponíveis no mercado, quando existirem, são um aspecto que pode ser considerado nas definições tecnológicas do livro digital a ser desenvolvido.

Outro fator primordial a ser considerado no processo de design do livro digital é o leitor. As definições relacionadas a este fator são majoritariamente ponderadas com as decisões relativas aos demais fatores primários, especialmente no que tange a experiência desejada ao usuário/leitor para leitura/uso quanto ao conteúdo e à tecnologia ${ }^{8}$, por exemplo. Igualmente os hábitos e características do público leitor, o alcance que a obra terá ao mesmo, bem como os requisitos de acessibilidade podem determinar aspectos relacionados aos demais supracitados fatores primários e vice-versa. Contudo, outros fatores também são relevantes para a devida compreensão e definição do público, como as opiniões do autor, visto que ambos podem estar intimamente ligados. Em que pese a ponta da recepção final, as definições quanto ao acesso e ao alcance do livro digital podem ser influenciadas pelas limitações e imposições das plataformas de distribuição ou das bibliotecas ${ }^{9}$, quando for o caso. Nesse sentido, exemplifica-se que o público pode auxiliar a definir as formas de distribuição e acesso da obra.

Como se pode perceber, as relações entre os fatores são circulares, onde estes se influenciam mutuamente e a complexidade das decisões projetuais no processo de design do livro digital é grande. As reflexões e ponderações direcionam a definições que variam de acordo com o contexto de projeto e as conexões podem gerar um número grande de questionamentos que não se limitam aos exemplos trazidos até aqui.

Por isso, para complementar a compreensão do framework e das relações entre os fatores, o Framebook também contempla subfatores (Figura 6). Assim, cada fator é especificado em um ou mais subfatores, que possibilitam entender com maior detalhamento a que aspectos se referem.

\footnotetext{
${ }^{8}$ É importante lembrar que a relação leitor e tecnologia sob o aspecto da experiência para leitura/uso envolve tanto questões subjetivas da experiência quanto questões relacionadas à ergonomia e à usabilidade.

${ }^{9}$ A relação entre leitor e biblioteca pode ir além da distribuição e acesso. Uma vez que esta pode atuar como agente de disseminação cultural, sua influência pode trazer diferentes impactos sobre as definições a respeito do público alvo da obra em desenvolvimento.
} 

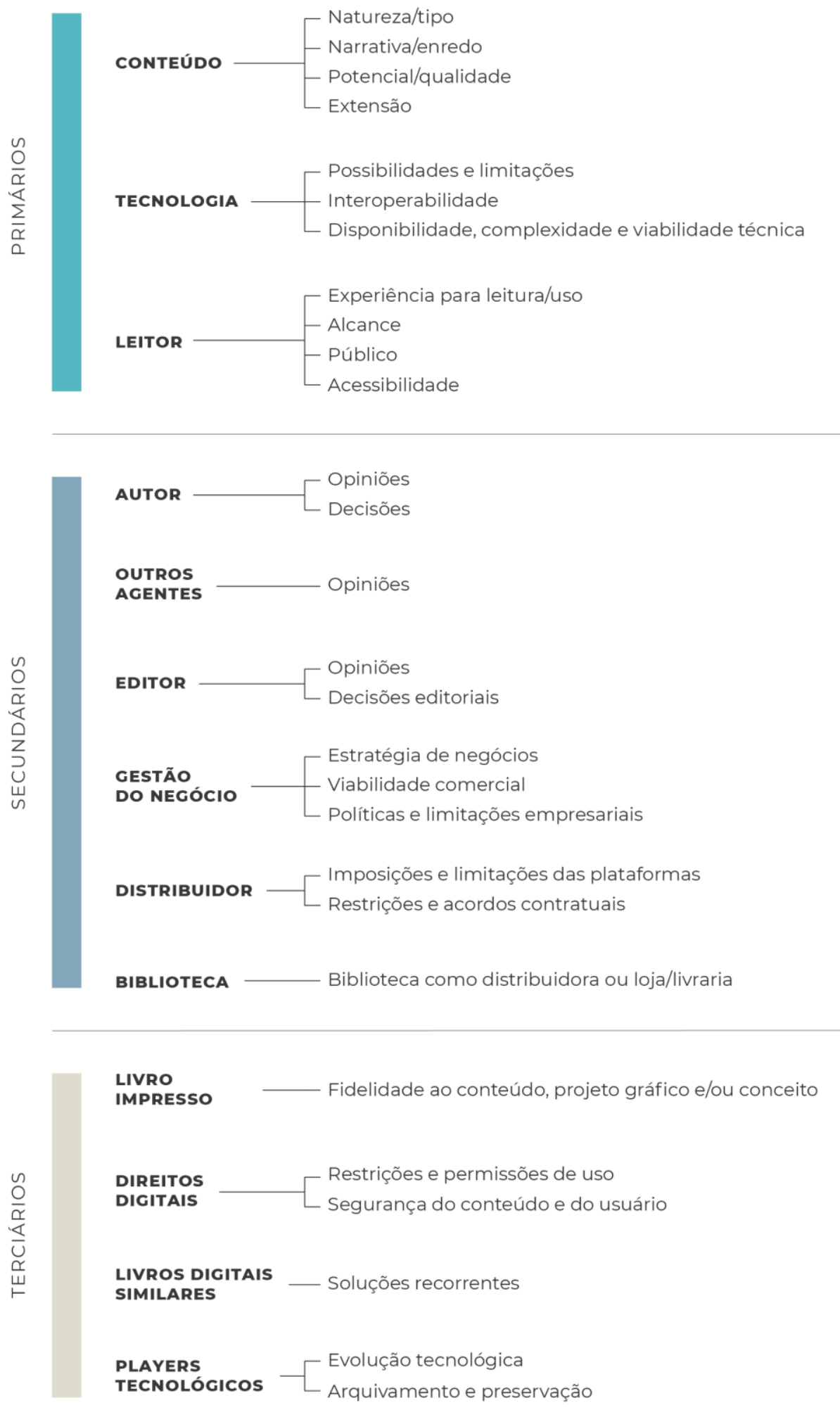

Figura 6: Subfatores do Framebook. Fonte: autores.

Por retratar um sistema aberto e dinâmico, o Framebook permite ainda a adição de novos fatores conforme a necessidade de cada projeto ou de acordo a evolução do sistema. É essencial que o designer ou a equipe determine a relevância do novo fator e as relações com outros fatores 
que forem pertinentes. Em função disso, a forma visual prevê novos espaços e permite rearranjos de modo a acomodar as expansões do sistema ou fatores e relações não previstas no Framebook (Figura 7).

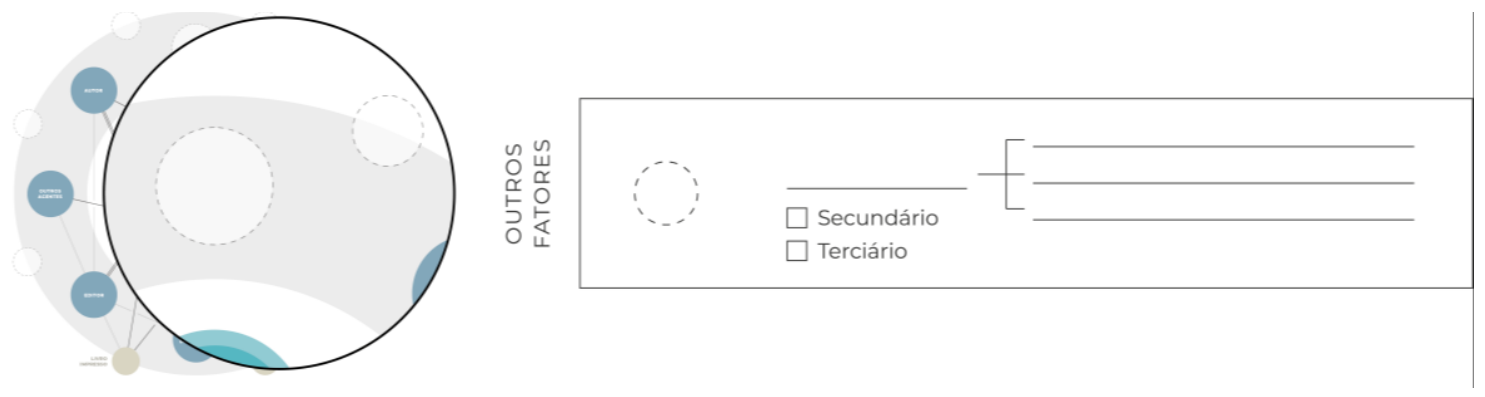

Figura 7: Possibilidade de adição de novos fatores e subfatores. Fonte: autores.

Nessa direção, é possível também adicionar novos subfatores aos fatores existentes. Em contrapartida, dada a flexibilidade da proposição, há a possibilidade de remover fatores secundários e terciários ${ }^{10}$, conforme a complexidade do contexto em que o processo de design ocorrer, compreendendo o efeito de desintermediação provocado pelo modelo digital de publicação. É fundamental reforçar que a adição ou a remoção de elementos no sistema podem alterar a organização do conjunto, afetando as conexões explicitadas na proposição. Logo, as relações não são permanentes, sendo sensíveis a perturbações e podem ser requalificadas ou até eliminadas frente ao movimento estrutural do sistema.

\section{Considerações finais}

Esta pesquisa partiu do contexto em que a existência do livro digital afeta os agentes da cadeia editorial tradicional e altera os processos de concepção, produção e distribuição, bem como a finalidade e a cultura associada ao livro. Diante dessa realidade em transformação, entende-se que é preciso reforçar a atenção ao processo de design do livro digital sob uma perspectiva sistêmica para que se compreenda a dinâmica dos fatores que lhe exercem influência e projetar livros digitais considerando as especificidades destes artefatos e a complexidade atual do contexto editorial. Nesse sentido, objetivou-se propor um framework para o processo de design do livro digital, a partir de uma perspectiva sistêmica.

Reforça-se que o framework foi concebido como um instrumento conceitual e sua utilidade se dá principalmente na visualização e na compreensão da complexidade e no planejamento do processo de design do livro digital. Dessa forma, o Framebook ${ }^{11}$ : (i) explicita os fatores que influenciam o referido processo, (ii) possibilita o planejamento de questões que the sejam pertinentes e (iii) auxilia na percepção da complexidade do processo, buscando minimizar os

\footnotetext{
${ }^{10} \mathrm{O}$ Framebook prevê a adição ou a remoção somente de fatores secundários e terciários, pois se entende que os fatores primários são imutáveis e indissociáveis e a exclusão de um destes ou a adição de um quarto fator descaracterizaria o sistema tal como modelado.

${ }^{11}$ Uma versão sintetizada está disponível em http://bit.do/Framebook.
} 
riscos de uma visão limitada ao artefato. A proposição é capaz de evidenciar a complexidade do processo de design do livro digital de maneira sistêmica, abrangente e flexível, tendo em vista as especificidades deste artefato e as transformações do sistema editorial, compreendendo múltiplos tipos de livro digital, dos mais simples aos mais sofisticados.

Quanto ao seu uso, o Framebook é direcionado a designers que atuam de forma individual ou a equipes de design em editoras e empresas de tecnologia, mas também pode ser utilizado por outros profissionais inseridos no contexto de Design. Nessa perspectiva, é interessante notar que o instrumento pode familiarizar outras profissões com o processo de design. Ademais, deve-se entender que a sistematização do processo, em sua complexidade, colabora com o desenvolvimento de livros digitais por equipes multidisciplinares, por se apresentar de forma modular com possibilidade de customização, que pode convocar experiências múltiplas, de inesperadas expectativas e percepções. Em razão disso, é possível afirmar que o objetivo da pesquisa foi cumprido.

É oportuno lembrar que nem todas as relações existentes entre os fatores primários, secundários e terciários foram explicitadas. Optou-se por mostrar aquelas inferidas com base na revisão de literatura e nas entrevistas com profissionais, bem como aquelas sugeridas pelos participantes do grupo focal, até o ponto que se considerou o limite para evitar o excesso de complexidade da representação e ao mesmo tempo para abranger com suficiência as relações consideradas pertinentes ao propósito do framework, sendo este um dos seus principais desafios. Além disso, destaca-se que tanto os elementos quanto as relações foram apontadas a partir do universo específico desta pesquisa, considerando seu objetivo e suas particularidades, sobretudo os resultados obtidos a partir das realidades dos participantes das entrevistas e do grupo focal. Diante disso, tal sistema está sujeito a alterações de acordo com outras perspectivas do mesmo contexto.

Por fim, esta pesquisa reforça que o livro digital deve ser entendido sobretudo como um sistema, o qual pode ser caracterizado pela inter-relação entre conteúdo, tecnologia e leitor e condicionado pela forma como cada um desses subsistemas possibilita a relação entre os demais. Ele também pode ser compreendido como parte de supra-sistemas tais quais o sistema editorial e o sistema contemporâneo de mídias. Esta noção contribui para a expansão da concepção de livro e corrobora a importância do pensamento sistêmico no contexto de Design na atualidade.

\section{Referências}

ANDRADE, A. L. O Curso do Pensamento Sistêmico. São Paulo: Digital Publish \& Print, 2014.

ARÉVALO, J. A.; CORDÓN-GARCÍA, J. A; DÍAZ, R. G. La autopublicación, un nuevo paradigma en la creación digital del libro. Revista Cubana de Información en Ciencias de la Salud, v. 25, n. 1, 2014, p. 126-142.

BARDIN, L. Análise de conteúdo. São Paulo: Edições 70, 2016.

BISTAGNINO, L. Design sistêmico: uma abordagem interdisciplinar para a inovação. In: MORAES, D.; KRUCKEN, L. Design e sustentabilidade. Cadernos de estudos avançados em Design. Barbacena, MG: EdUEMG, 2009. p. 13-29. 
CAPRA, F.; LUISI, P. L. A visão sistêmica da vida: uma concepção unificada e suas implicações filosóficas, políticas, sociais e econômicos. São Paulo: Cultrix, 2014.

CARDOSO, G. (org.). O livro, o leitor e a leitura digital. [s.l.]: Fundação Calouste Gulbenkian, 2015.

CLARK, G.; PHILLIPS, A. Inside Book Publishing. 5. ed. London: Routledge, 2014.

CORDÓN-GARCIA, J. A.; ARÉVALO, J. A. El libro como sistema: hacia un nuevo concepto de libro. Cuadernos de Documentación Multimedia, v. 26, p. 25-47, 2015.

CORDÓN-GARCIA, J. A. et al. Social Reading: Platforms, applications, clouds and tags. Witney, United Kingdom: Chandos Publishing, 2013.

CORDÓN-GARCÍA, J. A. La lectura digital y la formación del lector digital en España: la actividad de la Fundación Germán Sánchez Ruipérez y el Proyecto Territorio Ebook. Álabe, n. 13, 2016.

DE VOLDERE, I. et al. Mapping the Creative Value Chains: A study on the economy of culture in the digital age. Final report. Luxembourg: Publications Office of the European Union, 2017. Disponível em: https://publications.europa.eu/s/fo2x. Acesso em: 01 fev 2018.

DICK, M. E.; GONÇALVES, B. S. Representações e abordagens de apoio ao design do livro digital, p. 2640-2651 . In: Anais do $\mathbf{1 3}^{\circ}$ Congresso Pesquisa e Desenvolvimento em Design (2018). São Paulo: Blucher, 2019.

DUARTE, J.; BARROS, A. (orgs.). Métodos e Técnicas de pesquisa em comunicação. São Paulo: Atlas, 2012.

DUBINI, P. Voltare Pagina?. Le trasformazioni del libro e dell'editoria. Milan: Pearson, 2013.

FURTADO, J. A. A Edição de Livros e a Gestão Estratégica. Lisboa: Booktailors, 2009.

IDEO. Human Centered Design: kit de ferramentas. 2. ed. 2015. Disponível em: http://www.designkit.org/resources/1. Acesso em: 23 jan 2017.

MENDONÇA, S. O mundo económico do livro. In: CARDOSO, G. (org.). O livro, o leitor e a leitura digital. [s.l.]: Fundação Calouste Gulbenkian, 2015.

MOD, C. Designing books in the digital age. In: A futurist's manifesto: Essays from the bleeding edge of publishing. Boston, Massachusetts: O'Reilly Media, 2012. Retrieved March 29, 2018, from http://book.pressbooks.com/chapter/bookdesign- in-the-digital-age-craig-mod.

MOD, C. Post-artifact Books \& Publishing. 2011. Disponível em: https://craigmod.com/journal/post_artifact/. Acesso em: 29 mar 2018.

MORAES, D. Metaprojeto: o design do design. São Paulo: Blucher, 2010.

OLLAIK, L. G.; ZILLER, H. M. Concepções de validade em pesquisas qualitativas. Educação e Pesquisa. São Paulo, v. 38, n. 1, p. 229-241, 2012. Disponível em: http://www.scielo.br/pdf/ep/v38n1/ep448.pdf. Acesso em: 12 jul 2018.

PHILLIPS, A. Turning the page: The evolution of the book. Abingdon, Reino Unido: Routledge, 2014.

PINSKY, L. Os editores e o livro digital: o que está sendo feito e pensado em tempos do incunábulo digital. Livro - Revista do Núcleo de Estudos do Livro e da Edição, n.3, 2013.

POLO PUJADAS, M. Creación y gestión de proyectos editorials en el siglo XXI : del papel a la era digital. 2. ed. Cuenca : Ediciones de la Universidad de Cantabria : Edicions Universitat de les Illes Balears : Ediciones de la Universidad de Castilla-La Mancha, 2016.

PROCÓPIO, E. A revolução dos eBooks: a indústria dos livros na era digital. São Paulo: SENAI-SP editora, 2013. 
PWC. Turning the Page: The Future of eBooks. 2010. Disponível em: https://www.pwc.kz/en/publications/new_publication_assets/ebooks-trendsdevelopments.pdf. Acesso em: 23 jan 2017.

RODRIGUES, R. A tecnologia na edição digital. In: CARDOSO, G. (org.). O livro, o leitor e a leitura digital. [s.l.]: Fundação Calouste Gulbenkian, 2015.

SILVA, A. C.; BORGES, M. M. Hybrid publishing design methods for technical books. The Electronic Library, v. 34, n. 6, p. 915-926, 2016.

THOMPSON, J. B. Books in the Digital Age: The Transformation of Academic and Higher Education Publishing in Britain and the United States. Cambridge: Polity Press, 2005.

THOMPSON, J. B. Merchants of Culture: The Publishing Business in the Twenty-First Century. 2. ed. New York: Plume, 2012.

WISCHENBART, R. Ebooks 2018: Phase 02. The many faces of digital consumer books. A Global eBook White Paper. Viena: Ruediger Wischenbart Content and Consulting, 2018.

\section{Sobre os autores}

\section{Maurício Elias Dick}

Doutor em Design pela Universidade Federal de Santa Catarina (UFSC), é Professor Colaborador no curso de Design da Universidade do Estado de Santa Catarina (UDESC) e coordenador de projetos do Laboratório de Design da mesma instituição (LabDesign/UDESC). Pesquisador do livro digital e outras publicações digitais, possui interesse em design editorial, design digital, experiência do usuário (UX) e design de informação.

mauricioedick@gmail.com

\section{Berenice Santos Gonçalves}

Professora Doutora no Programa de Pós-Graduação em Design da Universidade Federal de Santa Catarina (UFSC), desenvolve pesquisas nas linhas de Mídia e Mídia e Tecnologia a partir dos seguintes eixos: "Interação e Interface", "Design Editorial no contexto das tecnologias digitais" e "Hipermídia para Aprendizagem". É líder do grupo de pesquisa "Publicações digitais" e vice-líder do grupo de pesquisa "Ambientes Hipermídia para apoio ao processo ensino aprendizagem".

berenice@ cce.ufsc.br 